\title{
Context effects and the recall of comparative sentences*
}

\author{
JOHN BENJAFIELD and LINDA GIESBRECHT \\ Brock University, St. Catharines, Ontario, Canada
}

\begin{abstract}
Clark and Card (1969) have proposed that semantic components underlie memory for comparative (C) sentences. To test this hypothesis, six groups of $15 \mathrm{~S}$ s each were given different sets of $\mathrm{C}$ sentences. In line with the theory, $\mathrm{S}$ s tended to remember unmarked adjectives better than marked ones and positive constructions better than negatives. However, contrary to the theory, they also tended to bias their responding either toward the negative or the equative form. A two-stage theory of recall, based on the memory schema-memory trace distinction. is proposed to account for these data.
\end{abstract}

Clark and Card (1969) have presented data supporting the hypothesis that $S$ s remember an abstract representation of comparative sentences. Clark (1969; Clark \& Stafford, 1969) has proposed that this representation consists of semantic features: "In many pairs of constructions one member differs from the other by having one additional semantic feature... Ss will often recall the simpler form in place of the more complex one, because the additional feature is easily lost from memory, and this causes $S$ s to reconstruct the semantically simpler form from the more complex [Clark \& Card, 1969. p. 45]." The simpler form is termed "unmarked," the complex form "marked."

These are the four basic types of comparative sentences: (1) comparative sentences containing unmarked adjectives, e.g., "The hot dog is better than the hamburger": (2) comparative sentences containing marked adjectives. e.g. "The hamburger is worse than the hot dog": (3) comparative equative sentences containing unmarked adjectives, e.g.. "The hot dog is as good as the hamburger": and (4) comparative equative sentences containing marked adjectives, e.g., "The hamburger is as bad as the hot dog." There are negative as well as the positive forms of each of these, yielding eight sentence forms in all.

Consistent with their theory. Clark and Card show that $\mathrm{Ss}$ recall more often and more accurately: (1) unmarked adjectives than marked ones: (2) positive constructions than negatives; and (3) sentences which embody a definite judgment (positive comparatives and negative equatives) than those which equivocate (negative comparatives and positive equatives).

In the Clark and Card study. S was presented with eight blocks of eight sentences each, each block containing one of each of the eight sentence forms. A test of cued recall followed each block. In the course of a pilot study done as a partial replication of Clark and Card's experiment. we found that when Ss were

*This work was supported by the National Research Council of Canada. The authors are grateful to Brian Doan for his help in the preparation of materials and the running of $S$ s. presented with four blocks of four sentences each (each block containing one of each of the four comparative forms), they recalled more negatives than positives. although they got approximately the same number of positives as negatives correct. While Clark and Card present evidence to show that their Ss did not try to recall only the easy constructions, our Ss biased their responding toward the more difficult negative constructions. Consequently, they did not remember more positives correctly.

The different results of the two experiments are in line with Bacharach and Kellas's (1971) suspicion that context effects are important in determining whether surface form or base structure (in this case semantic components) have the greatest effect on performance in memory tasks. If surface form and semantic components make different contributions to recall as the context changes, then Clark's explanation must be developed to account for these variations. The purpose of the present study was to explore the relative effects of these two variables in six different sets of comparative sentences. Specifically, where Clark and Card presented all Ss with all eight forms of comparative sentences. we presented different groups of Ss with different combinations of the four basic types.

\section{METHOD}

\section{Materials}

Four pairs of unmarked-marked adjective pairs were selected from the set Clark and Card used: happy-sad; clean-dirty: pretty-ugly; and good-bad. Sixteen noun triples were used to generate 16 comparative sentences and 16 recall cues. Thus, some Ss heard this cue and this sentence: "The books: Robin Hood isn't better than Little Women."

The 16 sentences had the following properties: four positive comparatives containing unmarked adjectives; four negative comparatives containing unmarked adjectives; four positive comparatives containing marked adjectives; and four negative comparatives containing marked adjectives.

Thirty-two additional sentences were generated by changing the comparative-unmarked adjective sentences to their equative-unmarked adjective and equative-marked adjective forms and by also changing the comparative-marked adjective 
Table 1

Mean Number of Sentences Recalled and Mean Number of Sentences Recalled Correctly of Each Type

\begin{tabular}{|c|c|c|c|c|c|c|c|c|c|c|c|c|c|c|c|c|}
\hline \multirow[b]{2}{*}{ Condition } & \multicolumn{2}{|c|}{$\begin{array}{l}\text { Lnmarked } \\
\text { Adjectives }\end{array}$} & \multicolumn{2}{|c|}{$\begin{array}{c}\text { Marked } \\
\text { Adjectives }\end{array}$} & \multicolumn{2}{|c|}{ Positives } & \multicolumn{2}{|c|}{ Negatives } & \multicolumn{2}{|c|}{ Definite } & \multicolumn{2}{|c|}{ Indefinite } & \multicolumn{2}{|c|}{ Equative } & \multicolumn{2}{|c|}{$\begin{array}{l}\text { Compar- } \\
\text { ative }\end{array}$} \\
\hline & Mean & $\mathrm{SD}$ & Mean & $\mathrm{SD}$ & Mean & $\mathrm{SD}$ & Mean & $\mathrm{SD}$ & Mean & SD & Mean & SD & Mean & $\mathrm{SD}$ & Mean & SD \\
\hline & \multicolumn{16}{|c|}{ Response Bias } \\
\hline Comparative-Linmarked/ & \multirow[t]{2}{*}{8.3} & & 5.9 & & 6.1 & & \multirow[t]{2}{*}{8.2} & & \multirow[t]{2}{*}{6.1} & & \multirow[t]{2}{*}{8.2} & & & & & \\
\hline Comparative-llarked & & 1.7 & & 1.3 & & 2.0 & & 1.5 & & 2.0 & & 1.5 & & & & \\
\hline \multirow{2}{*}{$\begin{array}{l}\text { Equative-Lnmarked/ } \\
\text { Equative-Marked }\end{array}$} & \multirow[t]{2}{*}{7.5} & & 5.6 & & 6.1 & & \multirow[t]{2}{*}{7.0} & & \multirow[t]{2}{*}{6.1} & & \multirow[t]{2}{*}{7.0} & & & & & \\
\hline & & 1.8 & & 1.5 & & 2.4 & & 3.0 & & 2.4 & & 3.0 & & & & \\
\hline \multirow{2}{*}{$\begin{array}{l}\text { Comparative-Lnmarked } \\
\text { Equative-Marked }\end{array}$} & \multirow[t]{2}{*}{6.1} & & 4.3 & & 5.6 & & \multirow[t]{2}{*}{4.8} & & \multirow[t]{2}{*}{5.8} & & \multirow[t]{2}{*}{4.6} & & \multirow[t]{2}{*}{6.8} & \multirow{2}{*}{\multicolumn{2}{|c|}{3.6}} & \\
\hline & & 2.0 & & 1.5 & & 2.4 & & 2.6 & & 2.4 & & 3.0 & & & & 2.1 \\
\hline \multirow{2}{*}{$\begin{array}{l}\text { Comparative-Marked/ } \\
\text { Equative-Unmarked }\end{array}$} & 8.2 & & 5.4 & & 7.4 & & 6.2 & & 7.3 & & 6.3 & & 8.1 & & 5.5 & \\
\hline & & 1.1 & & 1.5 & & 1.8 & & 2.4 & & 1.8 & & 1.5 & & 1.5 & & 1.7 \\
\hline Comparative-Unmarked/ & & & & & 6.7 & & 7.3 & & 8.2 & & 5.9 & & 8.3 & & 5.8 & \\
\hline Equative-Unmarked & & & & & & 2.4 & & 2.3 & & 2.3 & & 1.8 & & 3.1 & & 2.7 \\
\hline Comparative-Mlarked/ & & & & & 6.5 & & 5.8 & & 7.8 & & 4.5 & & 7.9 & & 4.4 & \\
\hline Equative-Marked & & & & & & 2.7 & & 1.8 & & 2.4 & & 2.3 & & 2.4 & & 2.4 \\
\hline & & & & & & & & erbati & n $\operatorname{Rec}$ & & & & & & & \\
\hline Comparative-Unmarked & 6.3 & & 4.9 & & 5.5 & & 5.7 & & 5.5 & & 5.7 & & & & & \\
\hline Comparative-Marked & & 1.3 & & 1.6 & & 1.8 & & 1.8 & & 1.8 & & 1.8 & & & & \\
\hline Equative-L'nmarked/ & 5.4 & & 4.3 & & 5.1 & & 4.6 & & 5.1 & & 4.6 & & & & & \\
\hline Equative-Marked & & 1.6 & & 1.8 & & 2.3 & & 1.6 & & 2.3 & & 1.6 & & & & \\
\hline Comparative-Lnmarked/ & 2.4 & & 2.5 & & 3.1 & & 1.9 & & 2.4 & & 2.5 & & 2.4 & & 2.5 & \\
\hline Equative-IIarked & & 1.4 & & 2.0 & & 1.5 & & 1.7 & & 1.3 & & 2.4 & & 1.4 & & 2.0 \\
\hline Comparative-Marked/ & 5.9 & & 4.3 & & 6.2 & & 3.9 & & 4.9 & & 5.3 & & 5.9 & & 4.3 & \\
\hline Equative-Lnmarked & & 1.6 & & 1.8 & & 1.3 & & 2.1 & & 1.4 & & 1.4 & & 1.6 & & 1.8 \\
\hline Comparative-Linmarked/ & & & & & 5.2 & & 3.9 & & 5.3 & & 3.8 & & 5.0 & & 4.1 & \\
\hline Equative-Unmarked & & & & & & 1.9 & & 1.2 & & 1.7 & & 1.3 & & 1.8 & & 1.7 \\
\hline $\begin{array}{l}\text { Comparative-Marked/ } \\
\text { Equative-Marked }\end{array}$ & & & & & 4.1 & 1.6 & 2.5 & 14 & 3.9 & 1.7 & 2.7 & 20 & 4.1 & 15 & 2.5 & \\
\hline & & & & & & 1.0 & & 1.4 & & 1.7 & & & & 1.5 & & 1.1 \\
\hline
\end{tabular}

sentences to their equative-unmarked adjective and equative-marked adjective forms.

\section{Procedure}

Each $S$ heard 16 of the sentences. played on a tape recorder. in blocks of 4 . Each of the sentences in each block was separated by a 3-sec interval. After each block, there was a $3-\mathrm{sec}$ interval. followed by the first noun cue. The $S$ then had $20 \mathrm{sec}$ in which to write down what he could remember, followed by the word "stop," than the next noun cue. and so on. After S had tried to recall the fourth sentence, the next block was presented, until $S$ had tried all 16 sentences. The $S$ wrote each sentence on a separate page of a booklet. He was not allowed to go backward and change his previous attempts.

The Ss were 90 undergraduate student volunteers at Brock Lniversity. Fifteen $\mathrm{Ss}$ were assigned randomly to each of six treatment conditions. The Ss were told to try to recall the sentences exactly, but. if they could not, to write down anything they could remember. The Ss were tested in groups of Sizes $3-15$.

\section{Experimental Design}

The six experimental groups each received a different set of sentences, formed by combining the four basic sentence types two at a time to yield six sets of 16 sentences each: (1) comparative-unmarked adjective and comparative-marked adjective: (2) comparative-unmarked adjective and equative-unmarked adjective: (3) comparative-unmarked adjective and equative-marked adjective: (4) comparative-marked adjective and equative-unmarked adjective: (5) comparative-marked adjective and equative-marked adjective: and (6) equative-unmarked adjective and equative-marked adjective.

The 16 sentences of each set were arranged in a 4 by 4 Latin-square design so that $S$ encountered one of each adjective pair in each block of 4 , of each construction in each block, and of each adjective pair in each construction. Thus, in each block, $S$ heard two positive and two negative constructions.

\section{RESULTS}

The mean number of sentences in each category recalled, as well as the mean number correctly recalled. are given in Table 1. Items included under "response bias" were recognizable comparison constructions containing at least one correct noun and the correct underlying adjective or its opposite. Items included under "correct recall" were recalled correctly verbatim.

In the four treatments in which Ss were presented with both marked and unmarked adjectives, they consistently preferred to use the unmarked forms $[F(1.56)=57.11 . p<.001]$ and. overall. remembered more sentences containing unmarked adjectives verbatim than they did those containing marked adjectives 
$[F(1,56)=14.60, p<.001]$.

Three of the four adjectives yielded more errors toward the unmarked than the marked form. The percentage of errors toward the unmarked form for pretty-ugly ranged from $88 \%$ to $100 \%$ across the four conditions; for good-bad from $90 \%$ to $100 \%$; for happy-sad from $83 \%$ to $100 \%$. For clean-dirty, however. Ss tended to recall dirty in place of clean, the percentage of such errors ranging from $60 \%$ to $100 \%$. This last finding was also present in the Clark and Card experiment. It may be that Ss regard "dirty" as unmarked, i.e., descriptive of the most frequently occurring, normal state of affairs, and "clean" as exceptional, or marked.

The Ss did not prefer positive over negative constructions $[F(1,84)<1$, n.s.], but they did get more positive than negative constructions correct $[\mathrm{F}(1,84)=$ 24.92, p<.001]. In the group given comparative-unmarked adjectives and comparative-marked adjectives, negative constructions were used as responses in recall more frequently than were positive constructions $[\mathrm{t}(14)=2.67, \mathrm{p}<.02]$. This finding replicates the aforementioned pilot study in which 18 Ss gave an average of 5.3 positive responses and 8.6 negative responses [ $\mathrm{t}(17)=2.80, \mathrm{p}<.02]$.

Although overall Ss preferred definite to indefinite constructions $[F(1.84)=4.15, p<.05]$. there was an interaction of Type of Construction Preferred by Condition $[F(5.84)=2.94 . p<.05]$, such that indefinite constructions were preferred in the group given comparative-unmarked adjectives and comparative-marked adjectives. The Ss did not get significantly more definite than indefinite constructions correct $[F(1,84)=1.03$, n.s. $]$

Finally, Ss preferred equative to comparative constructions $[F(1.56)=27.03 . p<.001]$ and also got more equative than comparative constructions correct $[F(1.56)=20.50, p<.001]$.

The number of recognizable comparative sentences produced varied widely between conditions $[F(5.84)=$ 4.41. $\mathrm{p}<.01]$, as did the number of sentences correctly recalled $[F(5,84)=10.82 . p<.001]$. These effects are neither surprising nor very interesting. given the fact that there is no reason to expect that all combinations of sentence forms will be equally easy to recall.

\section{DISCUSSION}

Put simply, Clark's theory maintains that over time the memory trace for comparative sentences decays to a simple unmarked form. The present study supports this notion in most respects. Both unmarked adjectives and positive constructions tend to be recalled correctly more often than their marked counterparts. Clark's model. however. predicts that definite constructions should be better recalled than indefinite ones, a prediction not consistently borne out in the present study. Further, the model does not account for the apparent preference for equative over comparative constructions. and the case in which negative constructions were preferred over positives.

The data can best be explained by exploring the implications of the distinction between trace memory and schematic memory (Paul, 1967). The memory trace for comparative sentences can be conceptualized as located within a schema or "setting" which is a function of the total set of sentences $S$ hears. This setting consists of an abstract representation of the "outstanding detail" (Barlett. 1935) which Ss select as characteristic of the material to be remembered. In this study, Ss seem to have tried to remember difficult items by selecting one of the longest surface forms of the set of sentences they heard as the most characteristic feature of the set and then biasing their responses toward that form. Thus, given both equatives and comparatives, Ss bias their responses toward the former. which have a longer surface form. Given only comparatives, Ss biased their responding toward the longer negative form.

The foregoing analysis suggests a distinction between memory for adjectives and memory for the surface form of the sentence. The former seems to be determined by the memory trace in the way Clark suggests, the latter jointly by the memory trace and the general setting. Thus, the effects of the lexical marking of adjectives seem to be quite general (Benjafield \& Doan, 1971). In the present study. memory for adjectives did not show any effects of context.

The general picture that emerges is one of a two-stage recall process. When $\mathrm{S}$ hears a noun cue, he then searches for the appropriate memory trace-which tends to be in a positive unmarked adjective form. However, his dominant impression of the whole set of sentences is either of negative or of equative constructions. Therefore. he biases his recall in one of those two directions. Thus. unmarked adjectives are recalled without bias, but positives may get changed to negatives when $S$ is given only comparatives, or $S$ tends to formulate his recall in an equative form when he is given both comparatives and equatives.

There were some minor procedural differences between this study and Clark and Card's (1969): we used auditory. they used visual presentation: we used paced. they used unpaced recall. These differences make stringent comparison of the two studies difficult. However. it seems reasonable to think that the reason why Clark and Card failed to find context effects like these may be due to the large number of sentences they used (eight per block). This may have prevented $S$ from abstracting characteristics of some of the members of the set which he then uses to exemplify the entire set. The present study suggests that when a smaller number of sentences are used, such abstractions are important in determining the final form of recall. In any event. further examination of context effects using larger sets of sentences in a design more closely approximating Clark and Card's (1969) would seem warranted. 


\section{REFERENCES}

Bacharach. V. R.. \& Kellas. G. Phrase versus base structure effects on short-term retention. Journal of Verbal Learning \& Verbal Behavior. 1971. 10. 171-175.

Bartlett. F. C. Remembering. Cambridge: Cambridge University Press. 1932.

Benjafield. J.. \& Doan, B. Similarities between memory for visually perceived relations and comparative sentences. Psychonomic Science. 1971. 24, 255-256.

Clark. H. H. Linguistic processes in deductive reasoning. Psychological Review, 1969, 76, 387-404.

Clark. H. H.. \& Card. S. K. The role of semantics in remembering comparative sentences. Journal of Experimental Psychology, $1969.82,545-553$

Clark. H. H.. \& Stafford. R. A. Memory for semantic features in the verb. Journal of Experimental Psychology. 1969, 80, 326-334.

Paul. I. H. The concept of schema in memory theory. In R. R. Holt (Ed.). Motives and thought: Psychoanalytic essay's in honor of Dalid Rapaport. New York: International Universities Press. 1967

(Received for publication September 26.1972; revision received November 27,1972 .) 